\title{
Supernumerary Ectopic Tooth in Nasal Cavity - A Case Report
}

\author{
Ahmed $\mathrm{Z}^{* 1}$ and Zubair $\mathrm{S}^{2}$ \\ ${ }^{1}$ Professor of ENT, Shalamar Medical \& Dental College, Lahore, Pakistan \\ ${ }^{2}$ House Officer, CMH-Medical \& Dental College Lahore, Pakistan \\ ${ }^{*}$ Corresponding author: Ahmed Z, Professor of ENT, Shalamar Medical \& Dental College, Lahore, \\ Pakistan, Tel: +92-3344551285, E-mail: zubmedke@hotmail.com \\ Citation: Ahmed Z, Zubair S (2015) Supernumerary Ectopic Tooth in Nasal Cavity - A Case Report. J Case \\ Rep Stud 3(4): 402. doi: 10.15744/2348-9820.3.402
}

Received Date: June 02, 2015 Accepted Date: August 07, 2015 Published Date: August 10, 2015

\begin{abstract}
Supernumerary ectopic teeth are not uncommon; they present in abnormal location in oral cavity or may occupy a more unusual position, such as Maxillary Antrum. They are often diagnosed as incidental finding on routine Radiography; however, few may be symptomatic. Treatment options vary from endoscopic removal to conventional extraction by dental surgeon. Presence of Ectopic tooth in nasal cavity is rare; very few cases have been described in literature. We present here a case of supernumerary ectopic tooth in nasal cavity which was mistaken as a case of foreign body nose and lead to complications.

Keywords: Ectopic Tooth; Supernumerary Nasal Cavity

Abbreviations: ENT: Ear Nose \& Throat
\end{abstract}

\section{Introduction}

Supernumerary teeth are those which exceed the normal dental formula [1]. They are not uncommon and are found in approximately $1.2-3 \%$ of population [2]. Prevalence varies from place to place and rate as high as $6 \%$ has also been reported [3]. They are more common in males and mostly involve permanent dentition. Maxilla is affected more often as compared to mandible; the most common site of involvement is anterior maxillary region [4].

While single supernumerary are common, multiple supernumerary teeth are often associated with various syndromes [5]. Rarely, they can been seen in non-syndromic patients as well [6,7].

Teeth are said to be ectopic when they do not follow normal path of eruption [8]. There may be minor variation in the path, for example as in crowding, but they are still within the oral cavity. Sometimes teeth may be found in totally ectopic location; for example many cases of ectopic teeth in Maxillary Antrum have been described [9].

Eruption of tooth into nasal cavity is very rare. Very few cases have been reported in literature [10,11]. We are presenting here a case of ectopic tooth in nasal cavity which was mistakenly treated as a case of foreign body in nose and lead to iatrogenic complications.

\section{Case Report}

A 25 year old male presented to us with the complaint of left sided nasal obstruction and headache off and on, since last one year. About 6 months ago, the patient consulted a junior ENT-Surgeon who diagnosed him as a case of foreign body left nasal cavity and attempted removal under general anesthesia; however, the attempt was unsuccessful, and lead to aggravation of symptoms. The patient was referred to us for further management.

On examination the nasal airways were reduced on both side but more so on left. The septum was deflected on left side and adhesions were seen in the left nasal cavity on anterior rhinoscopy. There was mass on the floor of nasal cavity covered with dry secretions and crusts; it was hard to touch on palpation with a probe and appeared fixed with floor of nose.

A CT-scan of the nose and paranasal sinuses was advised which revealed an ectopic tooth projecting into left nasal cavity (Figure 1). Furthermore, there was evidence of Maxillary sinusitis on the opposite side along with hypertrophy of Inferior turbinate and adhesions in the left nasal cavity (Figure 2). An orthopantogram (OPG) was advised for further evaluation; it showed that the teeth count was normal and the tooth projecting into the nasal cavity was supernumerary (Figure 3). Rest of the ENT examination was unremarkable; no abnormality was detected on general and systemic examination. 


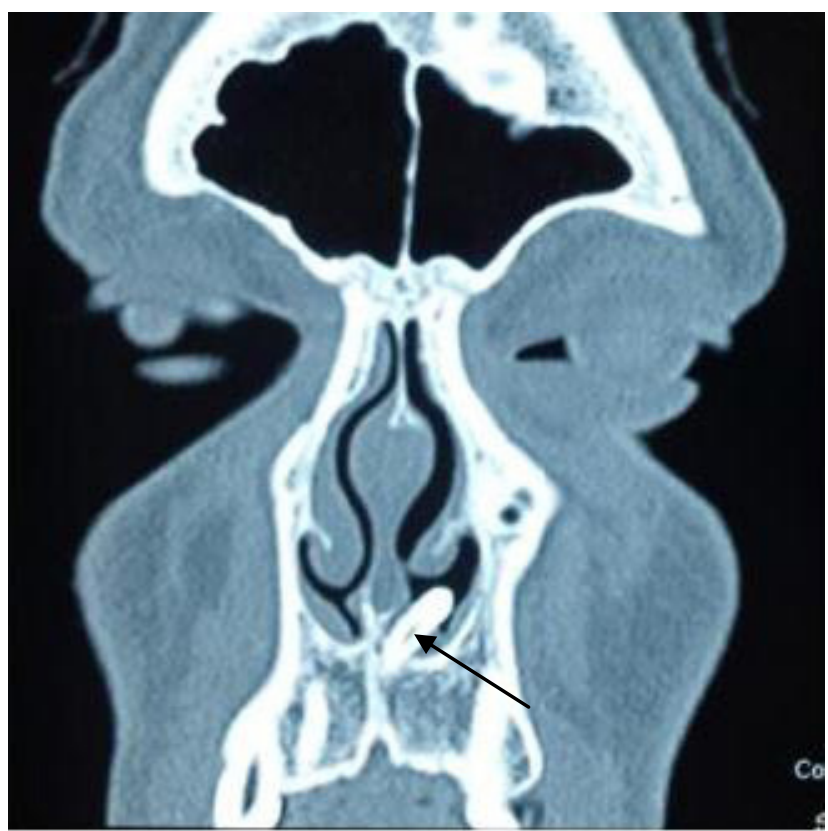

Figure 1: CT-Scan of Nose and Paranasal Sinuses (Coronal Section) showing Ectopic tooth projecting into left nasal cavity (Arrow)

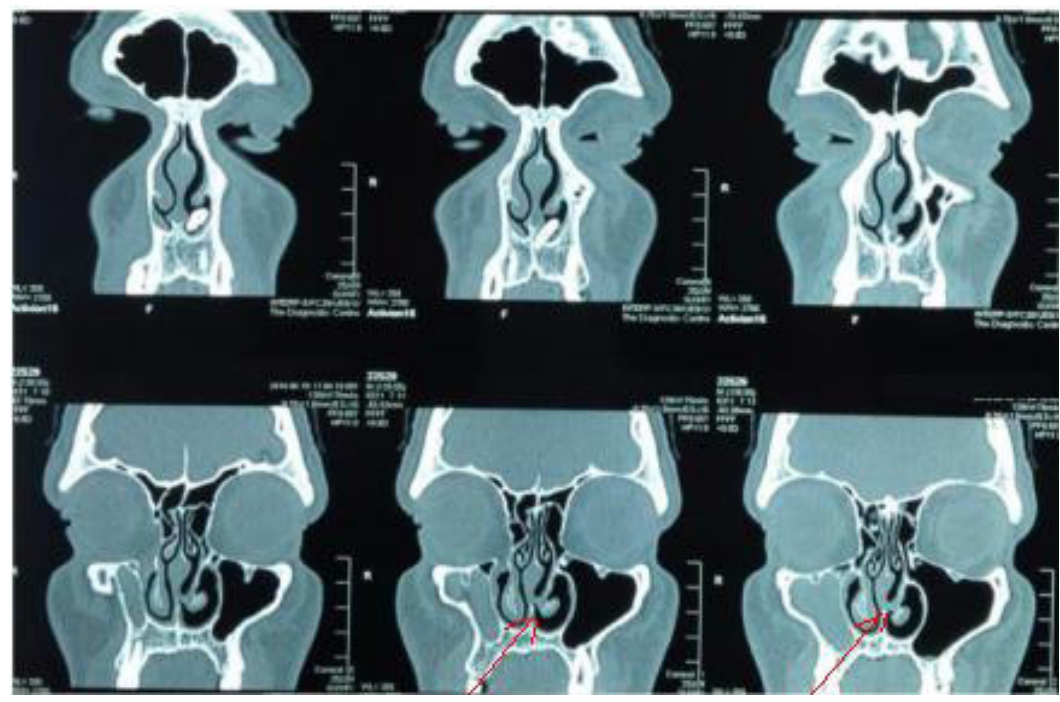

Figure 2: CT-scan Nose and Paranasal Sinuses (Coronal Sections) showing Maxillary sinusitis on right side and post-op adhesions in left nasal cavity (Red Arrow)

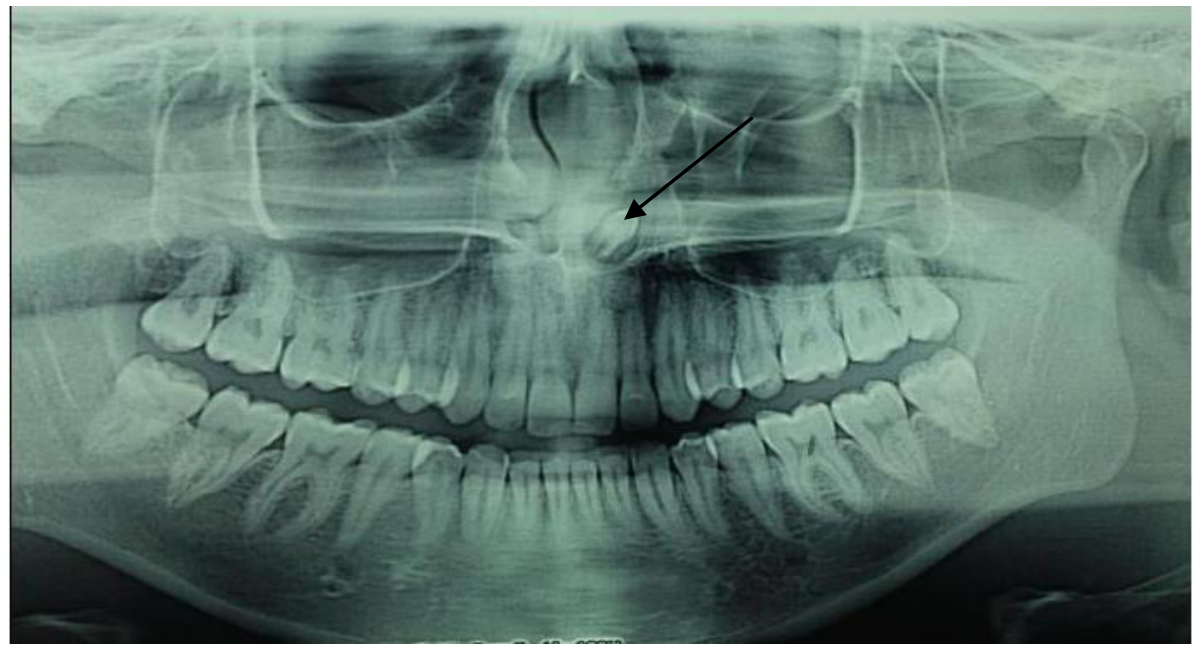

Figure 3: OPG of the patient showing normal teeth in dental arches along with supernumerary, ectopic tooth, above the root of first incisor on left projecting into nasal cavity (Arrow) 
The patient was re-operated under general anesthesia; tooth in the nasal cavity was easily removed with the help of an artery forceps, with application of gentle traction. The tooth had a smaller root and resembled a canine tooth (Figure 4). In addition; adhesions were removed with the help of electro Cautery: Septoplasty was performed to correct the septal deformity and an antral washout was performed to treat the opposite Maxillary sinus. As there was considerable shrinkage of the inferior turbinate after application of vasoconstrictor pack, hypertrophy was deemed to be compensatory and no additional procedure done for it. Splints were placed on both sides to prevent reformation for adhesion and nose was packed with Paraffin gauze. The patient was discharged the next day after removal of packs. Splints were removed after 2 -weeks. The recovery was smooth and uneventful.

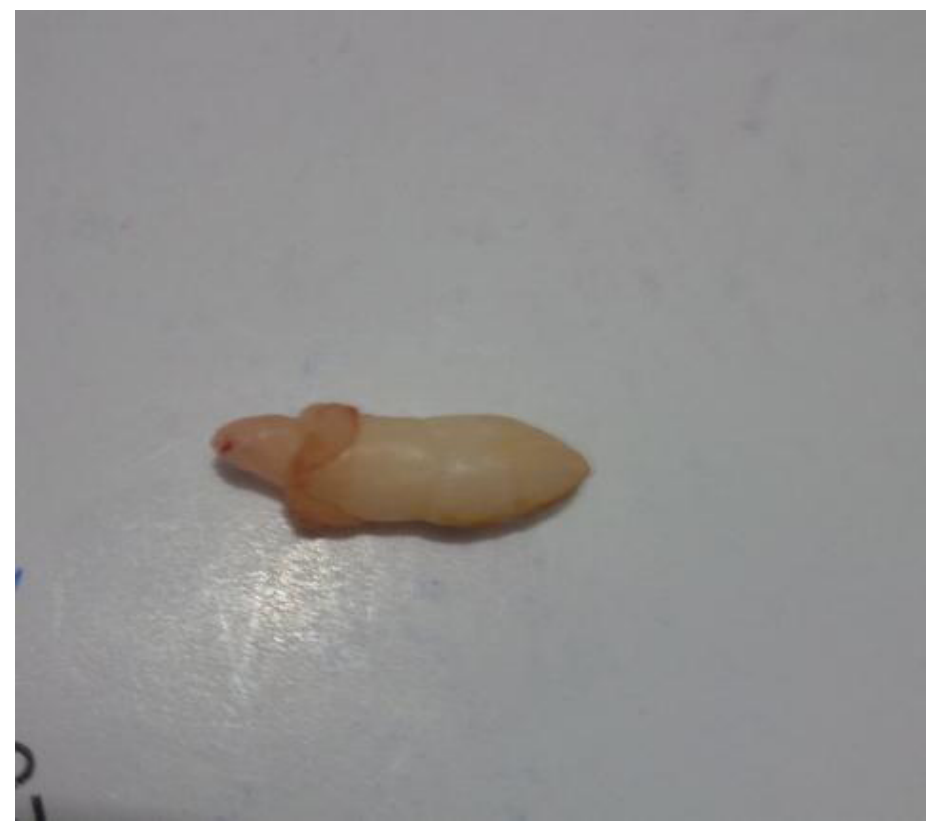

Figure 4: Removed ectopic tooth looking like a canine tooth

\section{Discussion}

Ectopic teeth have been described in literature as far back as 1923; Chapman described four cases of ectopic eruption of the maxillary first permanent tooth [12].

The etiology of ectopic eruption is debatable. Various environmental and genetic factors have been blamed. Apart from environmental factors, genetic factors are thought to play an important role [13]. However, there seems to be consensus that ectopic eruption is the result of disturbance in the balance between the rate of jaw growth, the rate of eruption of the first molars, and mean size of different teeth [8].

Though mostly asymptomatic, supernumerary teeth can be associated with various complications; they can lead to dental impaction, delayed eruption, ectopic eruption, overcrowding, spacing anomalies and the formation of follicular cysts [14].

Diagnosis of ectopic teeth is straight forward when they have erupted and present in the oral cavity; in unerupted state and when not associated with any complication, they may be detected by chance on routine Radiography. OPG is considered to be the most useful investigation for detection of supernumerary teeth [14].

Occasionally, however, ectopic teeth may create a diagnostic dilemma. Al Dhafeeri et al have described a case of ectopic tooth in the nasal cavity presenting with recurrent epistaxis [10]. Similarly Vámos et al have reported their association with facial pain and headache, when they were present in maxillary sinus [15].

Our case is interesting in the sense that the ectopic tooth was mistaken for a foreign body in the nose and considered to be the cause of nasal obstruction. An unsuccessful attempt for removal leads to the formation of adhesions and further aggravation of symptoms.

Treatment depends on the type and location of the supernumerary teeth and on its potential effect on adjacent structures [16]. If teeth are causing no complications and are not likely to interfere with orthodontic tooth movement, no treatment is required, except for regular radiological monitoring; this is usually the case when they lie beyond the dental apices [16]. However, they do require treatment if they are interfering with eruption or causing other complications. Extraction is the treatment of choice; care must be taken to avoid damage to the risk of damage to the adjacent roots [16]. However even when they are not causing any symptom or complication, the knowledge about their presence in such unusual locations may prevent undesired iatrogenic complications. 


\section{References}

1. Ata-Ali F, Ata-Ali J, Peñarrocha-Oltra D, Peñarrocha-Diago M (2014) Prevalence, etiology, diagnosis, treatment and complications of supernumerary teeth. J Clin Exp Dent 6: e414-8.

2. Anthonappa RP, King NM, Rabie AB (2013) Prevalence of supernumerary teeth based on panoramic radiographs revisited. Pediatr Dent 35: $257-61$.

3. Ratson T (2013) Diagnosis and treatment of supernumerary teeth in the premaxillary region: a literature review. Refuat Hapeh Vehashinayim 30: 26-30.

4. Schmuckli R, Lipowsky C, Peltomäki T (2010) Prevalence and morphology of supernumerary teeth in the population of a Swiss community. Short communication. Schweiz Monatsschr Zahnmed 120: 987-93.

5. Subasioglu A, Savas S, Kucukyilmaz E, Kesim S, Yagci A, et al. (2015) Genetic background of supernumerary teeth. Eur J Dent 9: 153-8.

6. Chen ZF, Wu JH, Zhao B, Hao XH, Wu JN (2006) Supernumerary teeth: report of a rare case and review of the literature. Shanghai Kou Qiang Yi Xue 15: 444-5.

7. Alvira-González J, Gay-Escoda C (2012) Non-syndromic multiple supernumerary teeth: meta-analysis. J Oral Pathol Med 41: 361-6.

8. Yaseen SM, Naik S, Uloopi KS (2011) Ectopic eruption - A review and case report. Contemp Clin Dent 2: 3-7.

9. Ramanojam S, Halli R, Hebbale M, Bhardwaj S (2013) Ectopic tooth in maxillary sinus: Case series. Ann Maxillofac Surg 3: 89-92.

10. Al Dhafeeri HO, Kavarodi A, Al Shaikh K, Bukhari A, Al Hussain O, et al. (2014) Recurrent epistaxis caused by an intranasal supernumerary tooth in a young adult. Am J Case Rep 15: 291-3.

11. Clementini M, Morlupi A, Agrestini C, DI Girolamo M, DI Girolamo S, et al. (2012) Endoscopic removal of supernumerary tooth from the nasal cavity of a child: a case report. Oral Implantol (Rome) 5: 21-5.

12. Chapman H (1923) First upper permanent molar partially impacted against second deciduous molar. Int J Ortho Oral Surg and Radio 9: 339-45.

13. Cakan DG, Ulkur F, Taner T (2013) The genetic basis of dental anomalies and its relation to orthodontics. Eur J Dent 7: S143-7.

14. Shah A, Gill DS, Tredwin C, Naini FB (2008) Diagnosis and management of supernumerary teeth. Dent Update 35: 510-20.

15. Vámos D, Ujpál M, Huszár T, Vaszilkó M, Németh Z (2012) Dentigerous cyst associated with a wisdom tooth in the maxillary sinus. Case reports, review of the literature. Fogorv Sz 105: 141-6.

16. Parolia A, Kundabala M, Dahal M, Mohan M, Thomas MS (2011) Management of supernumerary teeth. J Conserv Dent 14: 221-4.

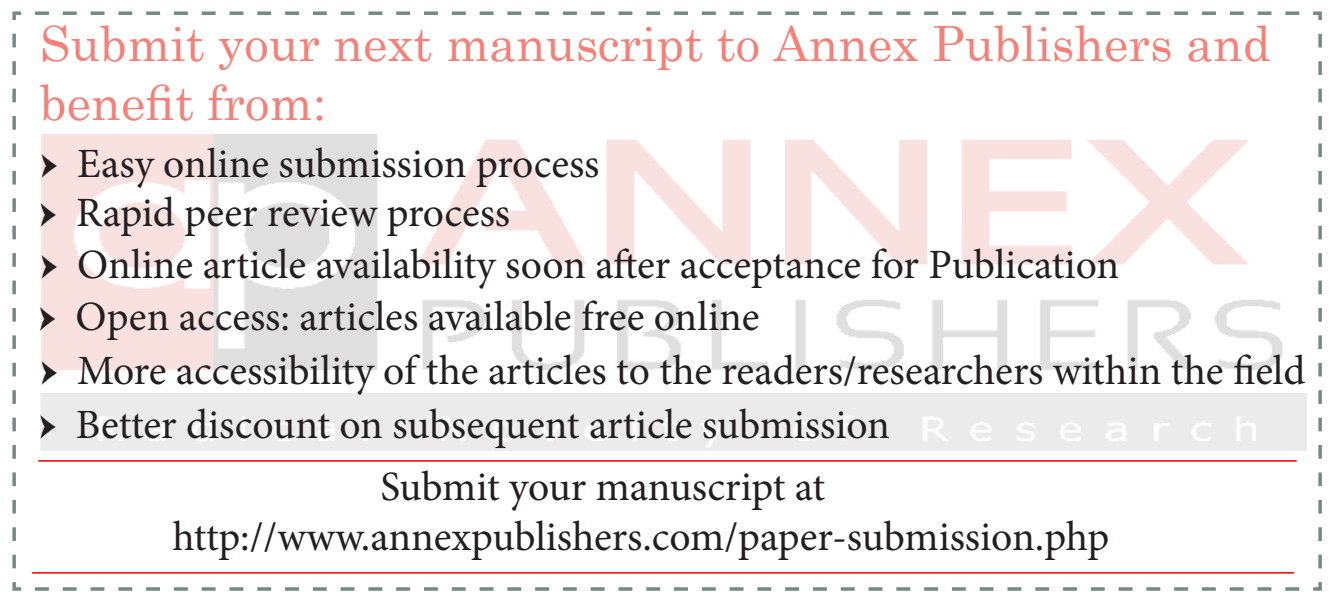

